\title{
EFFECT OF INTRAVENOUS TRANEXAMIC ACID ADMINISTRATION ON BLOOD LOSS DURING AND AFTER ELECTIVE CAESAREAN DELIVERY - A RANDOMISED PLACEBO-CONTROLLED STUDY
}

\author{
Subhrajyoti Chattopadhyay ${ }^{1}$, Susanta Sarkar², Sumit Chakrabarti3 , Mohanchandra Mandal ${ }^{4}$
}

${ }^{1}$ Associate Professor, Department of Anaesthesiology, North Bengal Medical College.

${ }^{2}$ Associate Professor, Department of Anaesthesiology, North Bengal Medical College.

${ }^{3}$ Consultant Obstetrician and Gynaecologist, Siliguri, West Bengal, India.

${ }^{4}$ Associate Professor, Department of Anaesthesiology, North Bengal Medical College.

\begin{abstract}
BACKGROUND
Despite much improvement in maternal health care, India and Nigeria together accounts for over one-third maternal deaths worldwide in 2015. Postpartum Haemorrhage (PPH) remains to be the major cause of maternal death in developing country. Strong evidence exists regarding efficacy of anti-fibrinolytic drugs such as Tranexamic Acid (TXA) in reducing blood loss during various surgeries. However, the level of evidence is poor regarding prevention and treatment of PPH with the use of TXA.
\end{abstract}

ABSTRACT

\section{MATERIALS AND METHODS}

The effect of single dose $(1 \mathrm{~g})$ intravenous infusion of TXA was evaluated in women aged 20 - 40 years with a singleton pregnancy at term (37 completed weeks) posted for elective Caesarean Section (CS). The study drug or placebo was infused over 5 minutes; 20 minutes before beginning of spinal anaesthesia.

\section{RESULTS}

Patients receiving TXA had significantly less blood loss compared with placebo group during intraoperative period as well as in the postoperative period up to 2 hours of postpartum $(499.1 \pm 111.2 \mathrm{~mL}$ vs $690.9 \pm 198.4 \mathrm{~mL}$ and $59.93 \pm 12.5 \mathrm{~mL}$ vs $110.06 \pm 13.47$ $\mathrm{mL}$, respectively ( $\mathrm{P}<0.001$ in both); indicating a reduction in blood loss by about $30 \%$ when estimating that in both intrapartum and postpartum periods (up to 2 hours). PPH was observed in six patients in the control group requiring 10 units of excess oxytocin infusion each, while none suffered PPH in TXA group. Adverse effects of TXA such as nausea, vomiting and diarrhoea were comparable between the two groups. None developed signs of thrombosis.

\section{CONCLUSION}

Immediate preoperative single dose TXA $(1 \mathrm{~g})$ reduces the amount of blood loss during and after lower segment CS. No serious adverse event was observed. Foetal outcome evaluated by Apgar score was not adversely affected.

\section{KEYWORDS}

Caesarean and Vaginal Deliveries, Human, Female, Postpartum Haemorrhage, Prevention, Tranexamic Acid, Treatment.

HOW TO CITE THIS ARTICLE: Chattopadhyay S, Sarkar S, Chakrabarti S, et al. Effect of intravenous tranexamic acid administration on blood loss during and after elective caesarean delivery - A randomised placebo-controlled study. J. Evolution Med. Dent. Sci. 2017;6(16):1286-1292, DOI: 10.14260/Jemds/2017/279

\begin{abstract}
BACKGROUND
Child birth is a time for happiness and fulfilment in a parent's dream, but sometimes this dream can turn into a nightmare owing to the harsh reality of maternal mortality. In 2015, the Maternal Mortality Ratio (MMR) - defined as the number of maternal deaths per 100,000 live births - was estimated at 216 globally. This translates into approximately 830 women dying every single day owing to the complications of pregnancy and childbirth. Of the 830 daily maternal deaths, 550 occurred in Sub-Saharan Africa and 180 in Southern Asia compared to 5 in developed countries. ${ }^{1}$
\end{abstract}

Financial or Other, Competing Interest: None.

Submission 17-01-2017, Peer Review 08-02-2017,

Acceptance 16-02-2017, Published 23-02-2017.

Corresponding Author:

Dr. Subhrajyoti Chattopadhyay,

C/o. Mr. Satyajit Chakroborty,

$2^{\text {nd }}$ Floor, Trinayani Apartment,

Taltala, Arabinda Pally,

Siliguri--734006,

West Bengal.

E-mail: drsubhra1972@gmail.com

DOI: $10.14260 /$ jemds $/ 2017 / 279$
Developing regions (low-resource settings) account for approximately $99 \%(302,000)$ of the global maternal deaths in 2015 with Sub-Saharan Africa alone accounting for roughly $66 \%(201,000)$ followed by Southern Asia $(66,000){ }^{1}$

At the country level, Nigeria and India are estimated to account for over one-third of all maternal deaths worldwide in 2015 with an approximate 58,000 maternal deaths (19\%) and 45,000 maternal deaths (15\%), respectively. Mothers' death owing to complications during pregnancy and childbirth has decreased by $43 \%$ from an estimated 532,000 in 1990 to 303,000 in 2015. ${ }^{1}$ Between 1990 and 2015, the global MMR declined by only $2.3 \%$ per year between 1990 and 2015. In some countries, annual declines in MMR were above $5.5 \%$ between $2000-2010 .{ }^{2}$ In UK, the MMR is reported to be 8.54 per 100,000 maternities in $2012-14$ trienniums. Overall, there was no statistically significant decrease in the maternal death rate in the UK between 2009 11 and $2012-14 .^{3}$

Haemorrhage after Caesarean Delivery (CD) causes increased maternal morbidity and mortality. In order to reduce this morbidity and mortality, it is important to reduce blood loss during and after CD. ${ }^{4}$ Management of haemorrhage after CD may range from administration of oxytocics and 
blood transfusion to more radical measures like hysterectomy.5,6 Radical measures like hysterectomy can have a profound impact on the psyche and health of the mother. Even, transfusion of blood products exposes mothers to the risk of transfusion-related adverse effects. Concern about safety of blood transfusion, continual shortage in supply and the rising cost of blood bank operations - all have instigated us to consider ways to reduce transfusion requirements before and after surgery.

Prophylactic use of anti-fibrinolytic drugs such as tranexamic acid (TXA) has been shown to be very effective in reducing blood loss in various surgeries. ${ }^{7}$ Although strong evidence through numerous studies exist regarding effectiveness of TXA in reducing blood loss during different surgeries, the level of evidence is insufficient regarding the efficacy of TXA for the prevention and treatment of PPH. The data regarding benefit-harm ratio is also poor in this obstetric field. ${ }^{7}$ This indicates the need for further observations. Hence, the present study was designed to evaluate the effect of single dose intravenous TXA compared with placebo (Ringer's lactate solution) administration in reducing blood loss during and after elective $\mathrm{CD}$ in terms of intraoperative blood loss, amount of blood loss for the duration of two hours after the $\mathrm{CD}$ and the amount of oxytocin required.

\section{MATERIALS AND METHODS}

The study was carried out among the pregnant mothers admitted in the labour ward of the Department of Obstetrics and Gynaecology of a Speciality Clinic in a Metropolitan City of North-East region of India. Women aged 20 - 40 years with a singleton pregnancy at term (37 completed weeks) posted for elective CS and those attending antenatal care clinics as regular basis were recruited for the present study.

\section{Exclusion Criteria}

i. Pregnancy complications like pre-eclampsia, polyhydramnios, macrosomia, multiple pregnancy, preterm labour.

ii. Abnormal placenta such as placenta praevia and abruptio placentae.

iii. Severe medical and surgical complications involving the heart, liver or kidney, brain disease, blood dyscrasias, coagulation disorders and severe anaemia.

iv. History of thromboembolic disorders.

v. Allergy to the study drug (TXA).

\section{Sample Size}

Sample size was calculated assuming that a difference of 100 $\mathrm{mL}$ of total (intra- and post-operative) blood loss would be a clinically important difference between the two groups. It was calculated that 45 subjects would be required per group in order to detect this difference with $80 \%$ power and $5 \%$ probability of type 1 error. Standard deviation was assumed to be 190 for control group and 150 for the test group on the basis of earlier study. ${ }^{8}$ Adjusting for $10 \%$ dropout rate, recruitment target was set at 50 subjects per group. The total sample size was 100 subjects; divided into two groups - study and control, 50 subjects in each group.

\section{Study Design}

The patients of this randomised, placebo-controlled, openlabel clinical study were randomised into two groups using a computer generated randomisation list to receive either $1 \mathrm{~g}$ (in $10 \mathrm{~mL}$ ) of intravenous (IV) TXA dissolved in $20 \mathrm{~mL}$ of Ringer's Lactate (RL) solution (study group; $n=50$ ) or IV placebo i.e. $30 \mathrm{~mL}$ of RL solution (control group; $\mathrm{n}=50$ ).

\section{Study Technique}

The study was initiated after getting approval from Institute's Ethics Committee. Informed consent was taken from each subject in writing before starting the trial. The family members of the patient were also counselled.

Detailed history taking and clinical examination were done along with checking of antenatal records. Patients fulfilling inclusion criteria were recruited for the study and randomly allocated into study and control groups. Either TXA or placebo was infused over 5 minutes; 20 minutes before beginning of spinal anaesthesia. Following delivery of the baby, all patients received 10 units of oxytocin in $500 \mathrm{~mL}$ of normal saline, infused intravenously over 20 to 30 minutes. Next bottle of IV fluid also contained another $10 \mathrm{U}$ oxytocin. Additionally, all patients received 15 units of oxytocin $5 \mathrm{U}$ in each bottle of IV fluid for three consecutive bottles over a period of 12 hours postoperatively). Further administration of oxytocin was according to requirement, i.e. if bleeding was severe or if the uterus was not contracted; additional $10 \mathrm{U}$ of oxytocin were given. During $\mathrm{CD}$, after the draining the amniotic fluid completely and after delivery of placenta, blood was drained in a separate suction container. Dry and soaked mops and sheets were weighed by a sensitive weighing machine. Mean blood loss from mops and sheets was then calculated using the formula used by Gai et al. ${ }^{9}$ The amount of blood from mops and sheets = (weight of soaked material - weight of dry material)/1.05; where 1.05 is the specific gravity of blood at $37^{\circ} \mathrm{C}$. The amount of blood drained in the suction container after delivery of placenta was added to the above calculated value to get the total amount of intraoperative blood loss. After 2 hours of operation, the number of pads used and their total weight were noted. From the total weight of soaked pads, the total weight of equal number of dry pads was deducted and converted into $\mathrm{mL}$ from the formula ${ }^{9}$ to get the 2-hour postoperative blood loss. Pre- and post-operative complete blood count, Prothrombin Time (PT), Activated Plasma Thromboplastin Time (aPTT), serum urea and creatinine, serum bilirubin and liver enzymes (AST and ALT) levels were compared between the two groups.

\section{Specific Parameters}

Following parameters were compared between the test and the control groups -

i. Intraoperative bleeding, i.e. from delivery of placenta to the end of $\mathrm{CD}(\mathrm{mL})$.

ii. Postoperative bleeding, i.e. from end of CD to 2 hours postpartum $(\mathrm{mL})$.

iii. Total bleeding, i.e. from delivery of placenta to 2 hours postpartum (mL).

iv. Recording of any additional dose of oxytocin, if required.

v. Complete blood count, Bleeding time, Clotting time, PT, aPTT, serum urea and creatinine, serum bilirubin and 
liver enzymes (ALT and AST) - measured preoperatively and 24-hour postoperatively.

vi. Pre- and post-operative recordings of vitals viz. pulse rate, systolic and diastolic blood pressure, respiratory rate and pallor.

\section{Data Analysis}

After completion of the study, observed data were unblinded for entry into Microsoft Excel Sheet. Then it was analysed using Statistical Package for the Social Sciences (SPSS) for Windows (Version 12.0, SPSS Inc., Chicago, IL, USA). Statistical analysis was carried out using independent sample t-test (for continuous data) and the Pearson Chi-square test and Fisher's exact test (for categorical data) as appropriate. A preliminary test of normalcy was carried out (KolmogorovSmirnov test) to find out the distribution of the data. A twotailed observation was assumed. The value of $\mathrm{P}<0.05$ was considered as significant. After analysis, the continuous data were expressed as mean \pm SD and range (minimum to maximum value) for continuous data and as number of patients (\%) for categorical data as applicable.

\section{RESULTS}

The study spanned over a period of one year from May 2014 to April 2015. Data from all patients were available for analysis. The data were expressed as: mean $\pm \mathrm{SD}$, frequency and percentage.

\begin{tabular}{|c|c|c|c|}
\hline Parameters & Study Group (n=50) & Control Group (n=50) & P value \\
\hline Age (years) & $25.00 \pm 4.71(18-36)$ & $25.88 \pm 5.39(18-38)$ & 0.387 \\
\hline Weight $(\mathrm{kgs})$ & $65.22 \pm 5.58(53-75)$ & $64.86 \pm 8.48(49-83)$ & 0.803 \\
\hline Height $(\mathrm{mts})$ & $1.55 \pm 0.04(1.48-1.63)$ & $1.55 \pm 0.04(1.48-1.65)$ & 0.889 \\
\hline${ }^{*}$ Gravida: $1^{\text {st }} / 2^{\text {nd }} / 3^{\text {rd }}$ & $28(56) / 20(40) / 2(4)$ & $31(62) / 19(38) / 0(0)$ & $0.450 *$ \\
\hline *Parity: $0 / 1 / 2$ & $33(66) / 16(32) / 1(2)$ & $36(72) / 14(28) / 0(0)$ & $0.481 *$ \\
\hline POG (weeks) & $38.92 \pm 1.38(37-41)$ & $39.02 \pm 1.42(37-42)$ & 0.722 \\
\hline
\end{tabular}

A P value of less than 0.05 was considered as having statistically significant difference. Within parenthesis numbers indicate range (minimum to maximum value) for continuous data or number of patients (\%) for categorical data. POG, Period of Gestation during Caesarean delivery. Data are presented as mean $\pm \mathrm{SD}$, tested using independent sample t-test except marked *, which is expressed as number of patients (percentage) and the significance was calculated using Pearson Chi-square test and Fisher's exact test as appropriate. Study group ( $\mathrm{n}=50$ ) received $1 \mathrm{~g}$ (in $10 \mathrm{~mL}$ ) of IV tranexamic acid dissolved in $20 \mathrm{~mL}$ of Ringer's lactate solution. Control group $(\mathrm{n}=50)$ : received IV placebo, i.e. Ringer's lactate solution.

The difference in age, weight and height patients of both the groups was not statistically significant, signifying that these confounding variables were equally matched in both the groups. Also, the two groups were comparable with respect to gravida and parity, i.e. there is no significant difference in the distribution of primi- and multi-gravidae and nulli- and multi-parous women in the two groups. Mean period of gestation during CD was also comparable.

\begin{tabular}{|c|c|c|c|}
\hline Indication for Caesarean Section & Study Group (n = 50) n (\%) & Control Group (n = 50) n (\%) & P value \\
\hline $\begin{array}{c}\text { Post-dated pregnancy with } \\
\text { High floating head }\end{array}$ & $14(28)$ & $11(22)$ \\
\hline CPD & $13(26)$ & $14(28)$ \\
\hline Previous one/two CD & $9(18)$ & $11(22)$ \\
\hline Primigravida with breech & $9(18)$ & $8(16)$ \\
\hline \multicolumn{2}{|c|}{ Table 2. Distribution of Patients based on Indications for Elective LUCS } \\
\hline
\end{tabular}

Table 2. Distribution of Patients based on Indications for Elective LUCS

Significance calculated using Pearson Chi-square test. $\mathrm{P}<$ 0.05 is significant. CD, Caesarean delivery; CPD, Cephalopelvic disproportion.
The distribution of patients with respect to indication for elective caesarean section was found to be comparable in the two groups (Table 2).

\begin{tabular}{|c|c|c|c|}
\hline Parameters & Study Group (n=50) & Control Group (n=50) & P value \\
\hline *Pallor (Present/Absent) & $22 / 28$ & $29 / 21$ & $0.161^{*}$ \\
\hline Hb (gm\%) & $10.33 \pm 1.26(8.4-13.4)$ & $9.80 \pm 1.34(8.0-13.0)$ & 0.050 \\
\hline Total Count (per mL) & $9250.48 \pm 1391.16(6600-11000)$ & $9149.46 \pm 1271.68(6600-11000)$ & 0.706 \\
\hline Platelet Count (lacs/mL) & $2.1 \pm 0.62(1.2-3.5)$ & $2.16 \pm 0.62(1.2-3.5)$ & 0.589 \\
\hline PT (secs.) & $11.86 \pm 0.17(11.5-12.2)$ & $11.87 \pm 0.17(11.5-12.20)$ & 0.651 \\
\hline aPTT (secs.) & $31.53 \pm 0.93(30.0-33.2)$ & $31.51 \pm 0.86(30.0-33.2)$ & 0.894 \\
\hline \multicolumn{2}{|c|}{ Table 3. Pre-Operative Pallor and Haematological Parameters } \\
\hline
\end{tabular}

Data are presented as mean \pm SD (range, i.e. min-max), tested using independent sample ' $t$ '-test except marked * which is expressed as number of patients and the significance was calculated using Pearson Chi-square test. A P-value of less than 0.05 was considered as having statistically significant difference.

There was no significant difference in distribution of preoperative pallor in between the two groups, i.e. before 
operation the two groups were comparable with respect to presence or absence of pallor. The two groups were also comparable with respect to baseline haematological parameters (Table 3).

\begin{tabular}{|c|c|c|c|}
\hline Parameters & Study Group (n=50) & Control Group (n=50) & P value \\
\hline Pallor (present/absent) & $24 / 26$ & $38 / 12$ & 0.004 \\
\hline Hb\% (gm\%) & $10.08 \pm 1.18(8.2-13.0)$ & $8.81 \pm 1.18(7.0-12.0)$ & 0.000 \\
\hline $\begin{array}{c}\text { Hb\% difference } \\
\text { pre-op and post-op) }\end{array}$ & $0.26 \pm 0.22(0.00-0.90)$ & $0.99 \pm 0.48(0.10-2.00)$ & 0.000 \\
\hline Total Count (per mL) & $9354.80 \pm 1383.91(6700-11400)$ & $9243.20 \pm 1267.12(6700-11400)$ & 0.675 \\
\hline Platelet Count (lacs/mL) & $1.94 \pm 0.62(1.2-3.2)$ & $2.03 \pm 0.62(1.2-3.2)$ & 0.493 \\
\hline PT (secs) & $11.78 \pm 0.16(11.5-12.0)$ & $11.79 \pm 0.16(11.5-12.0)$ & 0.712 \\
\hline aPTT (secs) & $31.78 \pm 0.91(30.4-33.4)$ & $31.7 \pm 0.83(30.4-33.4)$ & 0.750 \\
\hline
\end{tabular}

Data are presented as mean \pm SD (range, i.e. min-max), tested using independent sample t-test. A P-value of less than 0.05 was considered as having statistically significant difference.

There was significant difference in postoperative haemoglobin levels between the two groups, mean concentration being 10.0 in study group versus $8.8 \mathrm{gm} \%$ in control group $(\mathrm{P}=0.000)$. Also, $\mathrm{Hb} \%$ change postoperatively is significantly more in control group (0.99 gm\%) versus study group $(0.26 \mathrm{gm} \%)(\mathrm{P}=0.000)$. Other parameters viz. total count, platelet count, prothrombin time and activated plasma thromboplastin time, did not have any significant difference in the two groups; $\mathrm{P}$ value $>0.5$ for all the parameters (Table 4). Other parameters of liver function tests and renal function tests (data not presented), did not have any significant difference in the two groups.

\begin{tabular}{|c|c|c|c|}
\hline Parameters & Study Group (n=50) & Control Group (n=50) & P value \\
\hline \multicolumn{5}{|c|}{ Intraoperative } \\
\hline Blood Vol. in Suction (mL) & $98.64 \pm 28.89(44-150)$ & $220.80 \pm 64.48(100-320)$ & 0.000 \\
\hline Blood Vol. in Mops + Sheets (mL) & $401.11 \pm 112.43(180.40-611.32)$ & $470.05 \pm 141.07(210.4-700.80)$ & 0.008 \\
\hline Total Intraop Blood Loss (mL) & $499.75 \pm 111.20(260.40-691.32)$ & $\begin{array}{c}690.85 \pm 198.41(319.10- \\
1020.8)\end{array}$ & 0.000 \\
\hline
\end{tabular}

\begin{tabular}{|c|c|c|c|}
\hline \multicolumn{1}{|c|}{ Postoperative } & 1020.8) \\
\hline 2 hrs. post-op Blood Loss & $59.93 \pm 12.5(40-82.5)$ & $110.06 \pm 13.47(80.4-146.8)$ & 0.000 \\
\hline \multicolumn{5}{|c|}{ Total Perioperative Blood Loss } \\
\hline Total blood loss & $559.68 \pm 113.80(319.40-745.32)$ & $\begin{array}{c}800.91 \pm 200.26(413.90- \\
1167.60)\end{array}$ & 0.000 \\
\hline \multicolumn{7}{|c|}{ Table 5. Perioperative Blood Loss } \\
\hline
\end{tabular}

Data are presented as (mean \pm SD) [range (min-max)]; independent sample ' $\mathrm{t}$ ' - test was used. A P value of less than 0.05 was considered as having statistically significant difference.

Significant less blood loss was observed in the study group in the intraoperative, postoperative as well as total perioperative period. The mean difference of blood loss between the two groups was $190 \mathrm{~mL}, 50 \mathrm{~mL}$ and $240 \mathrm{~mL}$, respectively; all are highly significant (Table 5 and Figure 1).

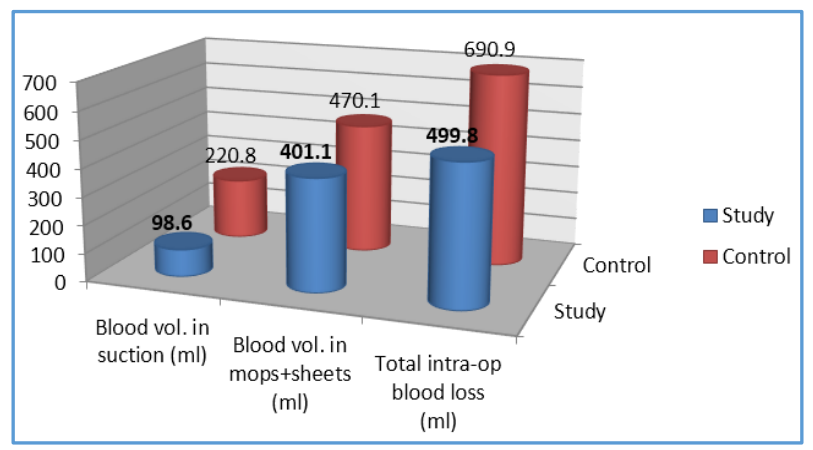

Figure 1. Intra-Operative Blood Loss (In $\mathrm{mL}$ )

\begin{tabular}{|c|c|c|c|}
\hline Parameters & $\begin{array}{c}\text { Study Group } \\
(\mathbf{n = 5 0 )}\end{array}$ & $\begin{array}{c}\text { Control Group } \\
(\mathbf{n = 5 0 )}\end{array}$ & P value \\
\hline Pulse (per min.) & $\begin{array}{c}81.64 \pm 8.17 \\
(68-96)\end{array}$ & $\begin{array}{c}84.04 \pm 6.92 \\
(68-96)\end{array}$ & 0.116 \\
\hline SBP (mmHg) & $\begin{array}{c}115.84 \pm 6.086 \\
(100-136)\end{array}$ & $\begin{array}{c}114.6 \pm 7.18 \\
(102-132)\end{array}$ & 0.324 \\
\hline DBP & $\begin{array}{c}74.12 \pm 6.080 \\
(60-84)\end{array}$ & $\begin{array}{c}73.76 \pm 8.7 \\
(60-90)\end{array}$ & 0.787 \\
\hline $\begin{array}{c}\text { Respiratory rate } \\
\text { (per min.) }\end{array}$ & $\begin{array}{c}13.64 \pm 1.396 \\
(12-16)\end{array}$ & $\begin{array}{c}12.92 \pm 2.10 \\
(10-16)\end{array}$ & 0.057 \\
\hline \multicolumn{4}{|c|}{ Table 6. Preoperative Vitals } \\
\hline
\end{tabular}

Data are presented as (mean \pm SD) [range (min - max)]; independent sample ' $\mathrm{t}$ ' - test was used. A P-value of less than 0.05 was considered as having statistically significant difference.

Preoperative vital parameters were comparable between the two groups (Table 6). Noticeable changes in mean Pulse rate was observed in control group, mean $84 / \mathrm{min}$ in study group versus $92 / \mathrm{min}$ in control group $(\mathrm{P}=0.000$ ) (Table 7). Other parameters like systolic blood pressure, diastolic blood pressure and respiratory rate did not have any significant difference in the two groups post-operatively (P value $>0.5$ ). 


\begin{tabular}{|c|c|c|c|}
\hline Parameters & $\begin{array}{c}\text { Study } \\
\text { Group } \\
\text { (n=50) }\end{array}$ & $\begin{array}{c}\text { Control } \\
\text { Group } \\
\text { (n=50) }\end{array}$ & P value \\
\hline Pulse (per min.) & $\begin{array}{c}83.76 \pm 7.52 \\
(70-98)\end{array}$ & $\begin{array}{c}91.6 \pm 5.07 \\
(80-100)\end{array}$ & 0.000 \\
\hline $\begin{array}{c}\text { SBP } \\
(\mathrm{mmHg})\end{array}$ & $\begin{array}{c}110.96 \pm 4.59 \\
(94-134)\end{array}$ & $\begin{array}{c}109.92 \pm 7.89 \\
(90-130)\end{array}$ & 0.124 \\
\hline $\begin{array}{c}\text { DBP } \\
(\mathrm{mmHg})\end{array}$ & $\begin{array}{c}68.44 \pm 6.011 \\
(60-80)\end{array}$ & $\begin{array}{c}69.32 \pm 7.22 \\
(60-80)\end{array}$ & 0.753 \\
\hline $\begin{array}{c}\text { Respiratory rate } \\
\text { (per min.) }\end{array}$ & $\begin{array}{c}14.38 \pm 1.22 \\
(12-16)\end{array}$ & $\begin{array}{c}14.00 \pm 1.71 \\
(12-18)\end{array}$ & 0.493 \\
\hline \multicolumn{2}{|c|}{ Table 7. Postoperative Vitals } \\
\hline
\end{tabular}

Data are presented as (mean $\pm \mathrm{SD}$ ) [range (min-max)]; Analysis was performed using independent sample ' $t$ ' - test. A P value of less than 0.05 was considered as having statistically significant difference.

The Apgar scores of new-borns at 1 and 5 minutes were $7.06 \pm 1.25$ and $8.66 \pm 1.00$ in the study group and $7.18 \pm 1.35$ and $8.64 \pm 0.98$ in the control group. Thus, there is no significant difference in the APGAR values at $1 \mathrm{~min}$ $(\mathrm{P}=0.559)$ and also at 5 mins $(\mathrm{P}=0.910)$ in both groups. None of the babies required NICU admission.

\begin{tabular}{|c|c|c|c|}
\hline Adverse Events & Study Group & Control Group & P value \\
\hline Nausea & 16 & 13 & 0.508 \\
\hline Vomiting & 09 & 08 & 1.135 \\
\hline Diarrhoea & 01 & 00 & 0.312 \\
\hline Signs of Thrombosis & 0 & 0 & - \\
\hline \multicolumn{2}{|r|}{ Table 8. Adverse Event Profile } \\
\hline
\end{tabular}

Data is presented as number of patients. Test applied: Pearson Chi-square test. $\mathrm{P}<0.05$ is significant.

The incidences of the adverse effects such as nausea, vomiting and diarrhoea were not significantly increased in the study group as compared to the control group (Table 8). This might indicate about the acceptable adverse event profile and safety for the use of TXA.

\section{DISCUSSION}

Maternal mortality is a health indicator that shows wide gaps between rich and poor, urban and rural areas, both between countries and within them. The risk of a woman in a developing country dying from a maternal-related cause during her lifetime is about 33 times higher compared to a woman living in a developed country.2,10 The tragedy lies in the fact that most of the deaths are preventable. The primary causes of maternal death are haemorrhage, hypertension, infections and indirect causes, mostly due to interaction between pre-existing medical conditions and pregnancy. During delivery of placenta, fibrinogen and fibrin are rapidly degraded, whereas plasminogen activators and Fibrin Degradation Products (FDP) increase due to activation of fibrinolytic system. This activation can last up to $6-10$ hours postpartum causing more bleeding. ${ }^{9}$ Antifibrinolytic agents prevent lysis of a blood clot or thrombus and thereby exert an anti-coagulant effect. Tranexamic Acid (TXA) is a synthetic derivative of the aminoacid lysine that exerts its antifibrinolytic effect through the reversible blockade of the lysine-binding sites on plasminogen and prevents its activation to plasmin, thereby prevents its combination with fibrin. ${ }^{11}$
The present study finds that TXA significantly reduces bleeding during the delivery of placenta as well as up to 2 hours postpartum. Intra-operatively, patients receiving TXA had significantly less blood loss compared with placebo group, $499.1 \pm 111.2 \mathrm{~mL}$ vs $690.9 \pm 198.4 \mathrm{~mL}$, respectively. There was reduction in blood loss in both intrapartum and postpartum periods. Coupling the two observations, patients in the study group had mean total blood loss (intra- and postoperative blood loss) of $559.7 \pm 113.8 \mathrm{~mL}$, while patients in control group had mean blood loss of $800.9 \pm 200.3 \mathrm{~mL}$. Thus, there was reduction in blood loss by about $30 \%$. There were six cases with PPH in the control group requiring 10 units of excess oxytocin infusion each, while none of the patients in TXA group had PPH. Gohel M and co-researchers ${ }^{11}$ also observed reduced bleeding in the intraoperative as well as 2 hours post-partum period in study group compared with the control group. They reported the quantity of blood loss in the study vs control group as $76 \mathrm{~mL}$ vs $133 \mathrm{~mL}$ in the intraoperative period and $373 \mathrm{~mL}$ vs $470 \mathrm{~mL}$ in the period from placental delivery to 2 hours post-partum. ${ }^{12}$ Gungordok $\mathrm{K}$ et $\mathrm{al}^{13}$ also reported that mean estimated blood loss was significantly lower in women treated with TXA $11 \mathrm{~g}$ prior to surgery) compared with those in the placebo group; $500 \pm 206$ vs $600 \pm 216 \mathrm{~mL}$, respectively).

Movafegh A et $\mathrm{al}^{8}$ found that $10 \mathrm{mg} / \mathrm{kg}$ of TXA administered intravenously 20 minutes before skin incision at Caesarean delivery led to reduced intraoperative bleeding $(262.5 \pm 39.6$ vs $404.7 \pm 94.4 \mathrm{~mL})$, postoperative blood loss $(67.1 \pm 6.5$ vs $141.0 \pm 33.9 \mathrm{~mL})$ and the consumption of intraoperative oxytocin infusion $(39 \pm 5.8$ vs. $43 \pm 5.4$ units; $\mathrm{P}=0.001)$. TXA was used in a fixed dose in the present study and the findings are in line with that. In another study ${ }^{9}$ when TXA was administered 10 minutes before the skin incision resulted in less bleeding 2 hours postoperatively $(42.8 \pm 40.5$ $\mathrm{mL}$ ) in the study group versus $74.98 \pm 77.1$ in the control), but did not show any decrease in post-placental delivery blood loss. TXA administration 10 minutes before skin incision in primipara patients resulted in reduced blood loss only in postoperative period, i.e. from the end of Caesarean section to 2 hours postpartum. ${ }^{4}$ This was probably due to the fact that TXA was administered only 10 minutes before the skin incision. Keeping the above facts in mind, the present study was designed to administer either TXA or placebo 20 minutes before beginning of spinal anaesthesia. Also, we used no such inclusion criteria based on parity.

In the present study, pallor developed in more number of patients in the control group in the postoperative period. There was also significant increase in pulse, mean $84 / \mathrm{min}$ in study group vs $92 / \mathrm{min}$ in control group. Other parameters like SBP, DBP and respiratory rate did not have any significant difference in the two groups $(\mathrm{P}>0.5$ for both the parameters). There was significant difference in postoperative haemoglobin levels between the two groups, mean concentration being $10.0 \mathrm{gm} \%$ in study group versus $8.8 \mathrm{gm} \%$ in control group ( $\mathrm{P}=0.000)$. The difference between the preoperative and postoperative haemoglobin values was also significantly lower in the study group than the control group, $0.26 \pm 0.22 \mathrm{gm} \%$ in study group versus $0.99 \pm 0.48 \mathrm{gm} \%$ in control group ( $\mathrm{P}=0.000$; highly significant). These results were consistent with the findings of Movafegh et $\mathrm{al}^{8}$ and Gai et al. ${ }^{9}$ 
The dosage regimes of TXA vary widely. When used for menorrhagia, the FDA recommended dosage is $1 \mathrm{~g}$ QDS for 4 days. The intravenous dosage is typically $0.5-1 \mathrm{~g}$ by slow injection three times daily. Alternatively, the initial dose 0.5 $1 \mathrm{~g}$ ) is followed by an infusion of $25-50 \mathrm{mg} / \mathrm{kg}$ over $24 \mathrm{~h}$. Dosing should be curtailed to $5-10 \mathrm{mg} / \mathrm{kg}$ IV in patients with renal failure. A single dose of $1 \mathrm{~g}$ appears to be sufficient for most adults in reducing surgical blood loss during the intraoperative and postoperative period up to 2 hours. Symptoms of overdose may be nausea, vomiting and orthostatic hypotension. In the present study, adverse effects of TXA such as nausea, vomiting and diarrhoea were not significantly more in the study group. Previous study also reports mild GI side effects like nausea, vomiting and diarrhoea in $16.3 \%$ of the population. ${ }^{13}$ No increase in incidence of thromboembolic events in the test group mothers or their babies were noted in any of the studies. ${ }^{4,8,9,12,14}$ None of these studies showed any adverse foetal outcome, as evident from the comparable Apgar scores in patients treated with TXA. A meta-analysis also reports that TXA reduces the amount of blood loss during CS without any adverse effect on neonates. ${ }^{15}$ In the present study, a single dose of $1 \mathrm{~g}$ (in $10 \mathrm{~mL}$ ) of IV TXA dissolved in $20 \mathrm{~mL}$ of Ringer's lactate solution was used.

The incidence of thrombosis during pregnancy and puerperium is $5-6$ times higher than that in the general population. When the antifibrinolytic drug TXA is administered, the increased risk of thrombosis should be considered, especially in the postpartum LSCS population. In the present study, not a single patient developed signs of thrombosis. Svanberg and coworkers ${ }^{16}$ reported 67 cases of abruptio placentae treated with TXA and none suffered from thrombosis. Bekassy $\mathrm{Z}$ and Astedt $\mathrm{A}^{17}$ used TXA to curtail down bleeding at conisation of cervix in 3014 women including 45 pregnant women and observed no thromboembolic episodes in their study. Other studies also report similar observations in this aspect.8,9,12

The safety of giving TXA (1 gm) remained a key concern, while the foetus was still in-utero. Hence, the neonatal outcome was meticulously evaluated by a neonatologist. In the current study, the mean Apgar scores at 1 and 5 minutes were comparable among the two groups. None of the babies required NICU admission. Results were comparable to previous studies. $4,8,9,12,13$ This data signifies that antenatal administration of TXA (20 minutes before spinal anaesthesia) is relatively safe for the neonate.

The level of evidence that TXA reduces the need for blood transfusion is strong, but the safety of routine use of TXA in surgical patients remains uncertain. The effect of TXA on thromboembolic events and mortality remains uncertain. ${ }^{18}$ In another recent study, Sentilhes $L$ et al ${ }^{19}$ comments that the current level of evidence is insufficient regarding the efficacy of TXA for the prevention and treatment of PPH, as are the data about its benefit: harm ratio. Researchers put emphasis on the need for large pragmatic clinical trial regarding the effect of routine use of TXA in a heterogeneous group of surgical patients and data collection on thromboembolic events and mortality. ${ }^{18-20}$ Needless to comment that more number of patients needs to be observed to draw any conclusion regarding the occurrence of less frequent adverse effect such as thrombosis. Large, adequately powered multicentre RCTs on TXA for preventing and treating PPH are warranted. These will provide adequate data for a prospective meta-analysis to resolve the uncertainties and to build up a concrete level of evidence.

\section{CONCLUSION}

TXA administered before induction of spinal anaesthesia significantly reduced the amount of blood loss during and after lower segment caesarean section. There were no cases of severe PPH (blood loss of $1000 \mathrm{~mL}$ or more) in the study group. None of the cases required blood transfusion or surgical intervention indicating that tranexamic acid was successful in preventing PPH. Its use was not significantly associated with any adverse drug reaction like nausea, vomiting, diarrhoea or thrombosis. Foetal outcome, as evaluated by Apgar score, was not adversely affected with the use of TXA. It can be used safely in patients during lower segment caesarean section in order to prevent $\mathrm{PPH}$.

\section{REFERENCES}

[1] Trends in maternal mortality. 1990 to 2015. Estimates by WHO, UNICEF, UNFPA, World Bank Group and the United Nations Population Division. [Executive Summary]. Available at: https://www.unicef.org/eapro/MMR_executive_summary_final_midres.pdf.

[2] Maternal mortality. Fact sheet, Updated November 2016. Available at:

http://www.who.int/gho/publications/world_health_ statistics/2016/whs2016_AnnexA_MaternalMortality. pdf.

[3] Knight M, Nair M, Tuffnell D, et al. On behalf of MBRRACE-UK. Saving lives, improving mothers' care surveillance of maternal deaths in the UK 2012-14 and lessons learned to inform maternity care from the UK and Ireland confidential enquiries into maternal deaths and morbidity 2009-14. Oxford: National Perinatal Epidemiology Unit, University of Oxford 2016.

[4] Sekhavat L, Tabatabaii A, Dalili M, et al. Efficacy of tranexamic acid in reducing blood loss after cesarean section. J Matern Fetal Neonatal Med 2009;22(1):72-5.

[5] Munn MB, Owen J, Vincent R, et al. Comparison of two oxytocin regimens to prevent uterine atony at cesarean delivery: a randomized controlled trial. Obstet Gynecol 2001;98(3):386-90.

[6] Hofmeyr GJ, Walraven G, Gulmezoglu AM, et al. Misoprostol to treat postpartum haemorrhage: a systematic review. BJOG 2005;112(5):547-53.

[7] Katsaros D, Petricevic M, Snow NJ. Tranexamic acid reduces postbypass blood use: a double-blinded, prospective, randomized study of 210 patients. Ann Thorac Surg 1996;61(4):1131-5.

[8] Movafegh A, Eslamian L, Dorabadi A. Effect of intravenous tranexamic acid administration on blood loss during and after caesarean delivery. Int J Gynaecol Obstet 2011;115(3):224-6.

[9] Gai MY, Wu LF, Su QF, et al. Clinical observation of blood loss reduced by tranexamic acid during and after caesarian section: a multi-center, randomized trial. Eur J Obstet Gynecol Reprod Biol 2004;112(2):154-7. 
[10] Maternal and reproductive health. Global Health Observatory (GHO) data. Available at:http://www.who.int/gho/maternal_health/en; Accessed on January 15, 2017.

[11] Dunn CJ, Goa KL. Tranexamic acid: a review of its use in surgery and other indications. Drugs 1999;57(6):1005-32.

[12] Gohel M, Patel P, Gupta A, et al. Efficacy of tranexamic acid in decreasing blood loss during and after cesarean section: a randomized case controlled prospective study. J Obstet Gynecol India 2007;57(3):227-30.

[13] Gungorduk K, Yildirm G, Asicioğlu 0, et al. Efficacy of intravenous tranexamic acid in reducing blood loss after elective cesarean section: a prospective, randomized, double-blind, placebo-controlled study. Am J Perinatol 2011;28(3):233-40.

[14] Reed MR, Woolley T. Uses of tranexamic acid. Contin Educ Anaesth Crit Care Pain 2015;15(1):32-7.

[15] Peitsidis P, Kadir RA. Antifibrinolytic therapy with tranexamic acid in pregnancy and postpartum. Expert Opin Pharmacother 2011;12(4):503-16.
[16] Svanberg L, Astedt B, Nilsson IM. Abruptio placentae treatment with the fibrinolytic inhibitor tranexamic acid. Acta Obstet Gynaecol Scand 1980;59(2):127-30.

[17] Bekassay Z, Astedt B. Treatment with fibrinolytic inhibitor tranexamic acid-risk for thrombosis? Acta Obstet Gynecol Scand 1990;69(4):353-4.

[18] Ker K, Edwards P, Perel P, et al. Effect of tranexamic acid on surgical bleeding: systematic review and cumulative meta-analysis. BMJ 2012;344:e3054.

[19] Sentilhes L, Lasocki S, Ducloy-Bouthors AS, et al. Tranexamic acid for the prevention and treatment of postpartum haemorrhage. $\mathrm{Br} J$ Anaesth 2015;114(4):576-87.

[20] Simonazzi G, Bisulli M, Saccone G, et al. Tranexamic acid for preventing postpartum blood loss after cesarean delivery: a systematic review and metaanalysis of randomized controlled trials. Acta Obstet Gynecol Scand 2016;95(1):28-37. 